\title{
Common Verbal and Non-Verbal Communication Practices in the Workplace of Multi-National Companies
}

\author{
Danilo A. Tabalan, Ph.D. \\ Social Sciences, Centre for General Education, AMA International University-Bahrain
}

\begin{abstract}
Communication is a process where two people or more than two people communicate with each other through speaking, writing etc. While verbal and written communication skills are important, research has shown that nonverbal behaviors make up a large percentage of our daily interpersonal communication. On the other hand, barriers in the language happen on people of different ethnic backgrounds, ages and experience. These barriers slow down communication and create misunderstandings that make communication ineffective, especially in the workplace. . It was from this perspective that the researcher intended to have this study to gain the insights and the real score on the failure and success of the multi-national companies in Bahrain in terms of verbal and non-verbal communication skills. The study is a qualitative research based from the case studies of the different multi-national companies which were selected to represent each sector in the Kingdom of Bahrain. This would certainly be benefiting the clients and the company, the educational institutions and the society as well. The findings and conclusions of this study were focused on the communication skills in the workplace which were varied and altering. The number of people and the differences in culture and race affected much the supposed common behavior and communication in the workplace. It is then recommended that race and cultural differences should be given considerations; communication skills should be strengthened; trainings and seminars should be conducted; and strict and proper supervision in the workplace should be improved and regulated.
\end{abstract}

Keywords: verbal communications, non-verbal communications, communications skills, English Competencies, Workplace Skills.

\section{INTRODUCTION}

In the workplace, the problems of communication can place the money and productivity of the company at stake of the company. Having no effective communication, the company cannot deliver information relevant to day-to-day operations and build a network to convey data of new products. Considering the issues of communication in the workplace can help create rules and regulations and policies addressing the problems and build effective network of communication in the office [1]. Business is benefited by a diversified workplace where multiple solutions could be drawn to settle company issues. However, the barrier in the language can create problem in communication in a diverse workplace. Misunderstandings could occur and make communication not effective [2].

Communication in the workplace has to be handled and designed professionally to sustain the continues growth and progress of an organization. Personal concerns and issues affecting the communication of the company should be avoided to prevent resolving problems it could create. Employees who do not communicate damage the company and hinder it from doing business and hamper its growth [3].

As a study, international companies will be benefited through the results of the research. They could have this study used as basis of the improvement of their companies especially in the workplace where they could build a culture of trust and honesty despite the diversity. Managers and supervisors could learn from the findings and adapt the recommendation for implementation for the company to be more productive and competitive in the global arena of business.

With the development of the manpower in the workplace, the good communication would lead to a peaceful working atmosphere and more productive working employees. As a result, this would certainly be benefiting both the clients and the company; for the clients, the quality of the products, and for the company, the flock of the clients and the accelerating profit.

The educational institutions could have their curriculum enhanced and develop more effective programmes for both the verbal and non-verbal communication through the English communication skill courses. This will be very significant in preparing and making the students ready to a long life learning and to undergo training for a more competitive and complex world after graduation. The society will be benefited too by the current research being undertaken. The government could encourage business firms to be conscious of their workplaces where everybody could change and be changed. The workplace is the reason of the companies for having quality service and quality production.

It is from this perspective that the researcher intended to have this study to gain the insights and the real score on 
the failure and success of the multi-national companies in Bahrain in terms of verbal and non-verbal communication skills. This study attempts to evaluate the verbal and nonverbal skills in the workplace of multi-national companies in the Kingdom of Bahrain. Specifically, the study attempted to: (a) identify the verbal and non-verbal skills demanded by employers across the chosen sectors; (b) determine the verbal and non-verbal skills and competencies required by employers in these sectors; (c) investigate the verbal and non-verbal skills and competencies that employees felt were needed for the job and what they currently possessed; and (d) produce a list of those skills and competencies needed in different sectors.

\section{REVIEW OF RELATED LITERATURE}

Communication is a process where two people or more than two people communicate with each other through speaking, writing etc. While good communication skills are significant, studies have shown that body language makes up a big percentage of our interpersonal communication [4]. Nonverbal communication can help one learn to read the nonverbal signals of other people and enhance one's own ability to communicate effectively. Communication is sharing information between two or more individuals, the act of conveying information. Because communication has so many components, failing to effectively communicate in the workplace is commonplace [5].

Verbal communication is the use of sounds and words in language form to convey a message, ideas and concepts and is vital to the processes of learning and teaching. Verbal communication acts as the primary tool for expression between two or more people in combination with nonverbal forms of communication [6].

The two basic types of verbal communication are interpersonal communication and public speaking. Interpersonal communication generally refers to a two-way exchange that involves both talking and listening, while public speaking involves one or more people delivering a message to a group [7].

According to Martin Remland, symbols and signs make up the verbal communication. Words are symbols while signs are results of the message [8]. Verbal communication is delivering a message to one or more recipients. It informs, inquires, argue and discuss all kinds of topics. It is essential to learning and teaching and creating rapport with other people [9]. Language barriers are the main reason of confusion when trying to communicate verbally. Since problems in communication can't be avoided, increase the confidence to communicate effectively. Think before one verbally communicates and respects the point of view of the recipient. Clearly speak and pronounce the words and be conscious of the eye contact, posture and facial expressions [10].

Everybody has his own style of communicating and understanding messages. Though verbal or oral communication is the prime way of expressing oneself, sign language could much influence the message delivered or perceived [11]. Efficient spoken communication is dependent on a number of factors and cannot be fully separated from other significant interpersonal like non-verbal communication. Clarity of speech, remaining calm and focused, being polite and following some basic rules of etiquette will all aid the process of verbal communication [12]. People can communicate information in numerous ways; so pay attention to things like eye contact, gestures, posture, body movements, and tone of voice. All of these signals can convey important information that isn't put into words. By paying closer attention to other people's unspoken behaviors, you will improve your own ability to communicate nonverbally [13].

Nonverbal communication is the transmission of information in addition to words in a communication. The sender conveys information to a receiver by means of body language, facial expression, posture, eye contact, gestures, tone of voice, touch and physical space [14]. It is the single most powerful form of communication. More than voice or even words, nonverbal communication cues one in to what is on another person's mind. The best communicators are sensitive to the power of the emotions and thoughts communicated nonverbally [15]. Nonverbal communication ranges from facial expression to body language. Gestures, signs, and use of space are also important in nonverbal communication. Multicultural differences in body language, facial expression, use of space, and especially, gestures, are enormous and enormously open to misinterpretation [16].

\section{METHODOLOGY}

This is a qualitative research which will be based from intensive case studies of the different multi-national companies within each sector in the Kingdom of Bahrain. A list of multi-national companies was drawn up and from which samples were chosen by the writer to have the actual distribution of sectors. The researcher sought permission from the companies to be the respondents of the study in coordination with the AMAIUB Research and Publication Office.

A checklist of common verbal and non-verbal communication skills (written and oral) linked with their workplace will be selected by the interviewees. These are as follows: writing skills - memo, report and request; verbal and non-verbal communication skills: fluency of the English language and sign language comprehension.

A semi-structured question was used as a survey instrument in the interview of the study. Case studies were undertaken to the selected business sectors in the Kingdom of Bahrain. An initial of 30 minute semistructured interview with a representative of the company comprised every case study. For accuracy, the final versions of the case studies were reviewed and checked. Varied methods were utilized to retrieve more sectoral validations and comments. 


\section{RESULTS AND DISCUSSION}

Communication in the workplace with anybody, follow no rules nor guidelines while talking in English. The use of communication skills in the workplace helps a worker to effectively communicate. Improper use of communication in the workplace could create problems at work, make people avoid you, or deliver confusing or wrong messages. Naturally, proper communication in the workplace is not too easy for those who are just learning English. Hereunder are the following case studies which were explored, studied and observed in different manners from the qualification and requirements, language skills, verbal and non-verbal communication skills, trainings and shortage of skills and turnovers.

\section{Case Studies on Business Sectors}

Case Study 1: Communication Skills on Commercial Department

Case study 1 is a commercial department of one of the business sectors in Bahrain and which has been operating for more than 20 years. There are 500 plus employees in the department. The respondent of the sector is an assistant operation manager. As a requirement, the respondent has both the language communication skills in English and Arabic. The position requires an applicant capable of verbally speaking and writing in English and able to relate non-verbally with the co- workers in the workplace. Generally, the assistant operation manager and the employees should have excellent communication skills and with a $\mathrm{C}$ or above grade requirement. Diploma is also necessary. A high school diploma at least. "However, some employers prefer those with a bachelor's degree in management operations, business administration and other management-related fields. Since the position is not uppermanagement, an employer may hire those with a high school diploma with a few years experience. More so, An assistant operations manager must have good organizational skills, leadership and interpersonal skills, advanced computer skills and analytical skills. He/she should be driven and goaloriented."

To be employed in the job, the applicant has to undergo language (verbal/non-verbal communication) skills test, delivery of communication test and accuracy of communication test. According to the respondent, body language, facial expression, eye contact and tone of voice are the most common non-verbal communication skills utilized in the workplace.

Job turnover is very minimal. This could be dependent on the capability of the person currently positioned and the incapability of the incoming applicant. The position is so critical that not anybody could easily possess requirements and qualifications suggested. Furthermore, trainings on the managerial job and the skills are strongly required.

Case Study 2: Communication Skills on Health and Safety Department

Case study 2 is a Health and Safety Department, another business sector in the Kingdom of Bahrain and has been operating for more than 10 years. There are 15 employees in the department. The respondent of the department is the Health and Safety Officer. As a requirement, the respondent is capable of three communication skills, English, Arabic and Indian. The position requires an applicant able to verbally speak and write in English and able to relate non-verbally with the co- workers in the workplace. The Health and Safety Officer and the employees should have excellent communication skills and with a $\mathrm{C}$ or above grade requirement. Diploma is also necessary. However, the international requirements suggest and seek for a bachelor's degree and very strong and credible credentials for somebody to be employed as Health and Safety Officer. He too must possess technical skills to execute the duties and responsibilities needed in the position.

As shown in the table above, the officer and the employees had demonstrated their communication skills in both speaking and writing skills and had exhibited body language, tone of voice and touch for non-verbal communication skills in the workplace. Furthermore, to be employed in the job, the applicant has to undergo language (verbal/non-verbal communication) skills test and delivery of communication test.

A Health and Safety Officer ("HSO") is responsible for monitoring a company's compliance with health and safety law and providing advice to both companies and employers on the work environment. This will involve both desk based monitoring as well as company visits.

Because of the high international requirements and because of the scarcity of the qualified applicants the turn-over of the position seems to be very minimal. The respondent, as the health and safety officer of the department, has trainings on First Aid and general HSE.

\section{Case Study 3: Communication Skills on Human Resource}

Case study 3 is the Human Resource with 8 employees. This has been operating for more than 10 years. As a requirement, the respondent of the sector is a Human Resource coordinator and who has both the language communication skills in English and Arabic. The position requires an applicant capable of verbally speaking and writing in English and able to relate nonverbally with the co- workers in the workplace. Generally, the Human Resource coordinator should have excellent speaking communication skills, above average writing skills and with a $\mathrm{C}$ or above grade requirement. Diploma is also necessary. To be employed in the job, the applicant has to undergo language (verbal/non-verbal communication) kills test, delivery of communication test and accuracy of communication test. According to the respondent, body language, facial expression, eye contact and tone of voice are the most common non-verbal communication skills utilized in the workplace.

In many cases and situations, most HR coordinators, of any level, have at least a bachelor's degree in business administration, preferably with a concentration in human resources management if an HR major is not 
available. Coordinators who are involved in company management may need an MBA, a master's degree in business administration. These degrees, too, may have a concentration in HR management. Conversely, although some coordinators can find work with only a high-school diploma, they often need work experience to compensate.

A human resources coordinator is responsible for handling hiring and employment services for a company, including recruiting and interviewing. He may also deal with payroll and benefits for employees. Depending upon the size of the organization for which he works, an HR coordinator may be a one-man department, oversee staff as a manager, or report directly to senior management [17]."The very high qualification and required skills of the job somehow diminish the rate of turnover in the position and where excellent speaking communication skills in English are also a necessity. Although no trainings were mentioned, still, trainings and seminars are very necessary most especially on management.

\section{Case Study 4: Communication Skills on Oil Processing Department}

Case study 4 is an Oil Processing Department where 65 workers are employed. This department has been operating for already more or less 20 years. The respondent of the sector is a supervisor. He is skilled in both English and Arabic communication. As a requirement, the applicant has to be verbally good in both speaking and writing in English and has to be also skilled in non-verbal communication especially in dealing with the employees in the workplace. The supervisor's communication skills require no high grade although a diploma is necessary. Hence an entry test on language (verbal/non-verbal communication) skills is nevertheless required.

Commonly, employers prefer high school graduate. Others go for degree holders. Sometimes, they consider candidates with leadership experience. They too need supervisors capable of both written and oral communication skills and who could make decisions and give solutions to the problems at hand. Trainings on English communication and business skills are required so much so as the training on fire and safety health [18]. There is a minimal turnover on the side of the supervisor. On the part of the workers, a quick turnover was observed. No language qualification was required.

Case Study 5: Communication Skills on Maintenance and Landscaping

Case study 5 is a business project on maintenance and landscaping with 24 employees. The business has been operating for almost 10 years. The respondent of the case study is a manager skilled in both English and Arabic languages. This sector requires the position with excellent communication skills, capable of verbally speaking and writing in English and able to relate non-verbally with the co-workers in the workplace. He has to have a grade of $\mathrm{C}$ and above in the language skills. To qualify in the managerial position, the applicant has to undergo language (verbal/non-verbal communication) skills test, management skills test, and interpersonal skills test. The respondent, being the manager, has with him trainings on language communication development and letter and report writing in both English and Arabic with an on-the-job training for three months.

While some small companies hire business managers based solely on experience, most companies require one to have formal education. A bachelor's degree in business administration or another applicable major may qualify him for management positions with various types of businesses, like marketing firms, financial institutions, retail stores, and manufacturers. Business managers apply their administrative and supervisory expertise to help companies increase profitability and productivity.

Good managers understand how employees learn, how they build relationships, how they think, and how they make decisions. To do this, qualified managers should be capable of communicating verbally and non-verbally and must have excellent interpersonal skills, including the ability to communicate clearly and listen empathetically. Strong managers embrace diverse skill sets and encourage other to do the same. The most qualified managers are able to make every employee feel valued and free to contribute creative solutions -even when those ideas run contrary to conventional wisdom [19]. Because of the lack of qualified skilled candidates for the position, there is a very minimal turnover in the job.

\section{Case Study 6: Communication Skills on Sales Department}

Case study 6 is a sales department of one of the business firms in Bahrain and which has been operating for more than 10 years. The department has 15 employees. The respondent of the department is a sales supervisor skilled with English and Arabic languages. He too has excellent communication skills and is capable of communicating verbally in speaking and writing and is able to relate non-verbally using body language, facial expression, eye contact, gestures and touch to the employees in the workplace. Furthermore, to be qualified in the position, the candidate has to have a bachelor's degree and a grade of C or above in language. More so, 5 years experience in sales is very significant to get the job. Entry tests on language (verbal/non-verbal communication) skills, management skills and interpersonal skills are required. After gaining the position, the supervisor is given trainings on communication skills and sales talk skills and techniques.

Sales supervisor supervises and coordinates the daily activities of sales representatives engaged in promoting and selling a product by phone or mail. He recommends changes to current sales techniques or procedures based on team performance and new selling techniques.

Turnover and skill shortage are dependent on the number of candidates possessing the skills. Oftentimes, the candidates lack the necessary skill, language communication skills [20]. 
Case Study 7: Communication Skills on Police Media

Case study 7 is the police media, a police department existing for more than 20 years and with only 6 employees. The respondent of the sector is a press photographer skilled in English and Arabic languages both in speaking and writing. Besides the verbal skills, the job is required to have the capability of non-verbally communicating with the workers in the workplace using body language, facial expression, eye contact, tone of voice and touch. The photographer should at least have a grade $\mathrm{C}$ or above in his language communication skills and a diploma. To finally do the task, the applicant should undergo language (verbal/nonverbal communication) skills test, comprehension skills test, delivery and accuracy skills test.

In the strict sense, possessing an associate's or bachelor's degree in photography may be required by many news businesses, and these degrees are particularly helpful for those seeking full-time positions. Coursework for these programs is a mixture of history, art and field application classes. Employers may also look for job experience. Internships, working on a school paper, entry-level assistant roles and freelance work can help news photographers build up a work reputation. Because of the lack of applicants capable of communicating in the English language both in speaking and writing, the job turnover is very minimal. Not everybody is gifted with such skills to shoulder the duties and responsibilities of the position. Trainings on communication skills and interpersonal skills are often one of the necessary requirements for the said position.

\section{Case Study 8: Communication Skills on Police Department}

Case study 8 is a police department with 60 working police enforcers. The respondent of the department is a policeman in both English and Arabic languages. As a police officer, he has the capability to communicate non-verbally using body language, facial expression, eye contact, gestures and touch to his co-policemen in the workplace. The policeman should at least get a grade of above average in his English communication skills and pass the language skills test, delivery of communication test and accuracy of communication test. The qualifications are supplemented with trainings on the use of weapons and holding checkpoints. To strictly follow the full requirements, an applicant to be police enforcer should at least have high school diploma, valid driver's license without restrictions except "A", 21 years old and no criminal record. He should be willing to submit to all questions and statements about himself and to all types of examination, physical or mental. The police enforcer should be skilled in both oral and written communication, could write clearly and should be physically fit for the job [21]. In this type of job, turnover is not anymore in question but the job is open to all who are able bodied, dedicated to the work; has quick and reasonable decisions during emergencies; has good memory recall of the details of the incident; and could effectively deliver significant functions of a police enforcer.

\section{Case Study 9: Communication Skills on Mail Section}

Case study 9 is the mail section, another department in a business sector with only 5 employees. It has been operating similar to the length of time as the other government agencies. The respondent of this sector is a mail sorter who has the capability of speaking and writing in both English and Arabic languages. The position also requires every applicant to be able to non-verbally communicate using body language, facial expression, eye contact, gestures, tone of voice and touch to his fellow workers in the workplace. Further, the applicant has to have a grade of above average in communications kills and $\mathrm{C}$ or above on the English language. Language communication skills test and comprehension skills tests are the entry points. Trainings on sorting usually follows, once the applicant is hired. Mail sorters help carriers organize their routes so residences and businesses receive their mail on time. Without them, the efficiency of the local post office may fall somewhere between the Pony Express and the high-volume producer in the 21st century. The no degrees requirement but language qualification and the few number of employees needed made the job turnover very minimal.

\section{Case Study 10: Communication Skills on Customer Service}

Case study 10 is a customer service which has been operating for more than 10 years. The respondent of the sector is a call center agent. As a requirement, the respondent has the language communication skills in English, Arabic and Indian. The position requires an applicant capable of verbally speaking and writing in English. Unlike the other jobs and positions, Call center agents demonstrate, if not very minimal nonverbal communication, no verbal communication at all is manifested. Generally, the assistant operation manager and the employees should have excellent communication skills and with a $\mathrm{C}$ or above grade requirement. Applicants have to pass language communications skills test, delivery of communication test and accuracy of communication test before he is hired for the job after which trainings on customer service, computer skills, cashier and accounting will have to follow. For more qualifications and requirements, the applicant should have and be skilled on the following: verbal communication, phone skills, listening, data entry skills, people skills, informing, customer focus, customer service, attention to detail, professionalism and multi-tasking. Most companies of call centers seek people who have inborn skills for the job for the reason that they could easily be trained for the task they are to undertake. Candidates are required to have communication skills, listening skills, computer and typing skills which are all assessed and evaluated in the process of application [22].

Turnovers on the job will highly be dependent on the qualifications of the call center agent in position and the qualifications of the candidates applying for the job. Thus, the call center will always be hiring better call center agents. Call center agents Establish insurance policies by obtaining client information; determining eligibility; and maintaining database. 


\section{CONCLUSIONS}

The study concludes then that most of the communication skills demanded by the employers were satisfied by the respondents representing the different departments of the business sector. The employed respondents possessed excellent communication skills, had a grade of $\mathrm{C}$ or above in the language skills and presented a diploma. The non-verbal skills were varied and dependent on the kind of job the respondent representative was employed. The employers seek employees who have bachelor's degree with organizational skills, leadership and interpersonal skills, computer skills and other related skills for a quality and productive output. Others require master's degree with very strong and credible credentials and technical and business skills. For some sectors, management skills and trainings are necessary. Though not exactly the same, most of the respondents had skills and competencies related to the employers' requirements and much so with the type of job they were employed. The respondents had managerial training, general health and safety training, language communication development, letter and report writing, sales talking, mail sorting, customer service training, computer skills training and cashier and accounting training respectively. With the skills and trainings that most of the employed respondents had, the length of service they had rendered the companies they were employed, the entry tests (language communication skills test, delivery of communication test, comprehension skills test, accuracy of communication test, management skills test and interpersonal skills test) they had undertaken before having the job and the minimal and slow turnover of positions would probably be an indication of job satisfying the needs of the company in terms of manpower and qualifications the respondent representatives currently have. With all these, a list of skills and competencies needed in different sectors are as follow: excellent communication skills in English, speaking and writing skills in English, $\mathrm{C}$ or above grade requirement in English language, bachelor's degree in management operations, business administration and other management-related fields, bachelor's degree and a very strong and credible credentials, master's degree in business administration (company) with HR management, administrative and supervisory expertise, good organizational skills, leadership and interpersonal skills, advanced computer skills and analytical skills, technical skills and goal oriented

The overall conclusions of this study are focused on the communication skills in the workplace which were varied and altering. The number of people and the differences in culture and race affected much the supposed common behaviour and communication in the workplace. Non-verbal communication is most of the time effective at times when no one wants to speak or nobody knows how to verbally communicate. In consonance with the given studies, it could be concluded that the multi-national companies lack guidance and supervision in the workplace. The requirements and qualifications could have been neglected and ignored in hiring and appointing the right person for the right job. The qualifications of the hired applicants seem not to have met the requirements for the targeted positions. To some sectors, turnovers were null due to the lack of qualified person needed in the job.

\section{RECOMMENDATIONS}

The following recommendations were drawn from the findings and conclusions of the study: (a) The employer has to consider the quantity and the differences in culture and race of the people in the workplace. (b) Strengthen both the verbal and non-verbal skills of the employees in the workplace. (c) Regular supervision and proper guidance should be implemented to hold control of misdemeanours and unlikable attitudes of the workers in the workplace. (d) Provide the right and proper trainings on all skills necessary to be develop the workers significant part in the productivity of the company.

\section{REFERENCES}

[1] Burgoon, J. K., Guerrero, L. K., \& Floyd, K. (2011), Nonverbal communication, Boston: Allyn \& Bacon.

[2] Segerstrale, Ullica., \& Molnar, Peter (Eds.). (1997). Nonverbal Communication: Where Nature Meets Culture. Mahwah, NJ: Lawrence Erlbaum Associates. ISBN 0-8058-2179-1

[3] Guerrero, L. K., DeVito, J. A., Hecht, M. L. (Eds.) (1999). The nonverbal communication reader. (2nd ed.), Lone Grove, Illinois: Waveland Press.

[4] Cherry, Kendra (psychology expert) (2015). Top Ten Nonverbal Communication Tips. Master the Art of Nonverbal Communication. Gretna, LA: Pelican Publishing Company.

[5] Beare, Kenneth (English as $2^{\text {nd }}$ Language expert) (2015). Workplace Communication Skills for ESL Learners. Overview. Boston: Allyn \& Bacon.

[6] Hanes, Tracii. (2001). Verbal Communication. What is Verbal Communication. August 16, 2013.

[7] Bull, P. E. (1987). Posture and Gesture. Oxford: Pergamon Press. ISBN 0-08-031332-9

[8] Remland, Martin S. (2009). Nonverbal communication in everyday life. Boston: Allyn \& Bacon.

[9] Heathfield, Susan M. (Human Resources expert) (2015). Communication in the Workplace. Basic Definition of Workplace and Interpersonal Communication. Boston: Allyn \& Bacon.

[10] Stubbs, K. H. (2003). Can't Get Through: 8 Barriers to Communication. Gretna, LA: Pelican Publishing Company.

[11] Gudykunst, W.B. \& Ting-Toomey, S. (1988) Culture and Interpersonal Communication. California: Sage Publications Inc.

[12] Hargie, O. \& Dickson, D. (2004) Skilled Interpersonal Communication: Research, Theory and Practice. Hove: Routledge.

[13] Knapp, Mark L., \& Hall, Judith A. (2007) Nonverbal Communication in Human Interaction. (5th ed.) Wadsworth: Thomas Learning. ISBN 0-15-506372-3

[14] Andersen, Peter. (2007). Nonverbal Communication: Forms and Functions (2nd ed.) Illinois: Waveland Press.

[15] Heathfield, Susan M. (Human Resources expert) (2015). Tips for Understanding Nonverbal Communication. Listen with your Eyes. Boston: Allyn \& Bacon.

[16] Fast, J. (1970). Body Language- The Essential Secrets of Nonverbal Communication. New York,NY: MJF Book.

[17] http://work.chron.com/qualifications-hr-coordinator-8546.html

[18] http://work.chron.com/supervisor-job-qualifications-7575.html

[19] http://learn.org/articles/What_are_the_Typical_Educational_ Requirements_for_Becoming_a_Business

[20] http://swz.salary.com/SalaryWizard/Sales-Supervisor-JobDescription.aspx

[21] http://www.wylietexas.gov/departments/jobs/police_officer_ qualifications.php

[22] http://hiring.monster.com/hr/hr-best-practices/recruiting-hiringadvice /job-descriptions 